\title{
Characteristics of the Defining Ability of the Elderly in Nouns, Verbs, and Adjectives
}

\author{
Ye Seul Kimª , Ji Hye Yoon ${ }^{\mathrm{b}}$ \\ ${ }^{a}$ Graduate School of Public Health, Hallym University, Chuncheon, Korea \\ ${ }^{b}$ Department of Speech Pathology and Audiology, Audiology \& Speech Pathology Research Institute, Hallym University, Chuncheon, Korea
}

Correspondence: Ji Hye Yoon, PhD

Department of Speech Pathology and Audiology, Hallym University, 1 Hallimdaehak-gil, Chuncheon 24252, Korea

Tel: +82-33-248-2224

Fax: +82-33-256-3420

E-mail: j.yoon@hallym.ac.kr

Received: January 6, 2016

Revised: March 31, 2016

Accepted: April 18, 2016

This work was supported by the National Research Foundation of Korea Grant funded by the Korean Government (NRF-2014S1A5A2A03065709).

\begin{abstract}
Objectives: Decline of semantic processing ability through aging affects our language defining ability which helps us to understand target vocabulary and draw upon related words. It is necessary to investigate defining ability in various Korean word classes such as verbs, adjectives, and nouns. This study attempts to investigate the defining ability of normal Korean elderly and compare their performance with that of younger people. Methods: The participants of this study were 45 elderly people and 45 young people. A total of 36 words were performed during a defining word task. Definition response scores, response times, definition types and error types were analyzed only for the words spoken within $30 \mathrm{sec}-$ onds. Results: First, with regard to definition response scores, the elderly group showed significantly lower performance in nouns, verbs and adjectives than the younger group. Second, the definition types of each word class showed significant differences between the age groups. Third, definition error types of each word class showed significant differences in concrete nouns, verbs and adjectives between the age groups. Fourth, the elderly group had significantly slower response times in concrete nouns, verbs and adjectives. Conclusion: These findings confirm that elderly groups have difficulty in recalling and generating new and different words in a communicative situation because of limitations on the diversity of their verbal language.
\end{abstract}

Keywords: Definition, Nouns, Verbs, Adjectives, Aging
65세 이상의 인구가 전체 인구 중 7\% 이상의 비율을 차지하는 것 을 고령화 사회라고 하는데, 우리나라는 2000년도에 고령화 사회 에 진입하여 현재는 $12 \%$ 의 비율에 도달하였으며, 2026년에는 초고 령 사회에 진입할 것으로 예상된다(Statistics Korea, 2015). 이러한 사회인구학적 변화로 인하여 다양한 분야에서 노화와 관련된 질 환에 대한 연구가 활발히 이루어지고 있으며, 더불어 정상 노화 과 정의 단계에 대한 신체적, 생리적, 인지적 특성을 밝히고자 하는 노 력과 관심도 증가되고 있다. 정상 노화 과정에 대한 특성을 확인하 고 정립하는 것은 임상 진단 측면에서 질환의 특성을 제시하는 것 만큼 중요할 수 있는데, 그 이유는 질환으로 인한 기능저하와 노화 로 인한 감퇴를 구별할 수 있는 바탕이 되기 때문이다.

정상 노화 과정에서도 뇌의 구조나 기능이 변화하면서 인지 기
능의 감퇴를 보일 수 있는데(Moon, 2001), 언어병리 분야에서는 특 히 이러한 인지 기능의 감퇴와 함께 언어 및 의사소통능력의 변화 에 주목할 필요가 있다. 언어영역은 크게 의미, 문법, 음운, 화용 등 으로 나뉘며 이 중에서 문법, 음운, 화용론적 측면은 학령기와 성인 기에 이르며 완성되면서 유지되는 양상을 보인다(M. B. Kim, 2014). 새로운 어휘의 의미를 습득하고 내용을 조직화하는 것과 관련이 있는 의미영역은 성인기 이후에도 지속적으로 발달하기도 하나 (McGregor, 2009; Paul \& Norbury, 2012; Vellutino, Fletcher, Snowling, \& Scanlon, 2004) 노년기에는 의미영역과 관련이 있는 활동(예: 이름대기)의 수행력이 감퇴할 수 있다(Kim \& Choi, 2012). 이러한 현상은 의미 지식(semantic knowledge)의 직접적인 감퇴보다는 ‘이 름대기'가이루어지는 과정에서 노화로 인한 의미-어휘사전(seman- 
tic lexicon)으로의 접근(access)이 원활하지 않거나 인출(retrieval) 단계에서의 결함에 기인한 것으로 보고되었다(Barresi, Nicholas, Tabor Connor, Obler, \& Albert, 2000; Cutting \& Ferreira, 1999). 따라서 노화로 인한 의미영역의 변화를 살펴보기 위해서는 어휘인 출 과정과 관계된 의미영역을 확인할 수 있는 다양한 과제를 사용 할 필요가 있다.

이러한 관점에서 ‘낱말 정의하기’ 과제는 제시되는 낱말에 대한 개념의 범위를 한정하고 명백히 밝히는 것으로, 기본적으로 해당 낱말을 구성하는 자질이나 개념을 파악하고 있음을 의미한다(Johnson \& Anglin, 1995). 또한, 해당 낱말의 특성과 의미를 보편적으로 표현하는 일반성과 다른 낱말의 개념으로부터 해당 낱말을 구별할 수 있는 특수성을 인식하는 것이 정의하기의 기본이 된다는 측면 (Bierwisch \& Kiefer, 1969)에서 의미영역을 간접적으로 살펴볼 수 있는 과제로 알려져 있다(Watson, 1985; Marinellie \& Johnson, 2004). 더불어 정의를 하는 활동을 통해 개념을 세밀히 파악하고, 다른 개념과의 의미적 연결을 통하여 정보를 통합하거나(Paul \& Norbury, 2012), 의미에 해당하는 적절한 어휘를 구성하고 배열하 기도 하므로(Watson, 1985) 일상의 의사소통 상황에서 대화의 핵 심을 파악하거나 정확한 내용으로 구현하는 것과 관련이 있을 수 있다. 따라서 노년층의 정의하기 능력을 확인하는 것은 의사소통 능력에 제약이 되는 부적절한 어휘의 사용을 설명할 수 있는 근거 중 하나가 될 수 있음이 영미언어권의 연구(Astell \& Harley, 2002; Hodges, Patterson, Graham, \& Dawson, 1996)를 통해 보고되었다. 같은 맥락에서 최근에는 한국어를 사용하는 경도인지장애 환자군 (Kim, 2015)이나 알츠하이머성 치매 환자군(Lim, 2010)과 같이 질 환이 있는 노년층의 명사 정의하기 능력이 인지기능과 밀접한 관련 이 있음이 확인되었다. 그러나 이러한 선행연구에서는 질환군에 보 다 초점을 맞추어 정의하기 특성을 확인하였으므로 정상 노인은 주로 통제집단의 역할로 제시되었다. 이에 Kim과 Choi (2012)는 현 존하는 언어평가의 하위검사영역에 정의하기가 포함되지만(Bowers, Huisingh, LoGiudice, \& Orman, 2004; Wallace \& Hammill, 2002; Wiig \& Secord, 1992), 그 분석 방법이 체계적이지 못함을 지 적하면서 정상 노년층의 명사 정의하기에 대한 체계적인 분석의 필 요성과 기준을 제시하였다. 그리고 노화로 인해 나타나는 언어장애 를 진단하거나 선별하는데 정의하기 능력이 중요한 준거로 사용될 수 있음을 역설하였다.

그러나 노년층을 대상으로 이루어진 위와 같은 선행연구들은 우 리나라에서 사용되는 품사 중 명사에만 초점을 두고 정의하기의 능력을 확인하였다. 우리나라 품사 빈도 순위를 조사한 연구(Choi, 2001; Kang \& Kim, 2004)를 살펴보면 순위의 후반부에는 연구마다
차이가 있으나 가장 높은 빈도의 순위를 구성하는 것은 명사, 동사, 형용사로서 세 가지 품사의 빈도를 합산하면 전체 품사의 $88.82 \%$ 로(Choi, 2001) 품사 중 상당히 높은 비율을 차지하고 있다. 명사는 사람이나 사물을 지칭할 때 사용되어 문장에서 주요 내용을 담당 하므로 의사소통에서 중요한 문장 구성성분이 된다(Lee, 2015). 동 사나 형용사는 명사를 도와 발화 내용을 풍성하게 만들어주므로 발화의 완성도와 관련이 있고 주로 주어의 행위나 상태를 설명하 는 역할을 한다(예: 명사=사자, 명사+동사 $=$ 사자가 달린다, 형용 사+명사+동사 $=$ 굶주린 사자가 달린다 $)(L e e, 2015)$. 그러므로 전반 적인 의사소통 능력의 임상적 확인을 위해서는 명사뿐만 아니라, 동사와 형용사의 정의하기 능력을 확인하고 정의하기 유형이나 오 류분석 등을 통하여 노년층의 정의하기에 나타나는 다양한 특성 을 살펴보는 연구가 필요하다. 본 연구에서는 명사, 동사, 형용사의 특성을 모두 반영한 분류 및 채점 기준을 통하여 각 집단에서 주로 관찰되는 정의하는 유형이나 오류 유형의 양상 및 정의하기를 개시 하는 시간까지 걸리는 반응시간을 비교하였다.

\section{연구 방법}

\section{연구대상}

본 연구의 대상자는 총 90 명으로 강원도와 서울에 거주하는 정 상 노인 45명과 청년 45명으로 하였다. 모든 대상자는 건강선별설 문지(Christensen, Multhaup, Nordstrom, \& Voss, 1991), 한국형 간이정신상태검사(Korean version of Mini-Mental State Examination, K-MMSE; Kang, Na, \& Hahn, 1997), 실어증-신경언어장애 선별검사(Screening Test for Aphasia Neurologic Communication Disorders, STAND; Kim, Hoe, Kim, \& Kim, 2009)를 통하여 정상 규준에 해당하는 성인만을 대상으로 하였다. 집단 간 교육년수 $(t=$ -1.699, $p>$.05), K-MMSE ( $t=-1.963, p>.05)$, STAND ( $t=-1.466$, $p>.05)$ 는 통계적으로 차이가 없었다. 대상자의 배경정보는 Table 1 에 제시되어 있다.

\section{검사 단어 선정}

검사 단어목록은 3 가지 품사(명사, 동사, 형용사)로 구성되었으 며, 난이도를 통제하기 위하여 빈도와 친숙도를 모두 고려하여 선 정하였다. 먼저 빈도의 경우, 각 품사당 한국어 사용 빈도에 대한 참 고문헌(Kang \& Kim, 2009)에서 200순위까지의 고빈도 어휘를 참 고하여 중간 순위를 기준으로 상위빈도 범주와 하위빈도 범주로 각각 100 개씩 단어를 나누었다. 친숙도의 경우, 언어병리학전공 대 학원에 재학중인 대학원생 6 명에게 200 개의 단어에 대한 친숙도를 
Table 1. Demographic information of participants

\begin{tabular}{lccllc}
\hline & \multicolumn{2}{c}{ Young group (N=45) } & & \multicolumn{2}{c}{ Elderly group (N=45) } \\
\cline { 2 - 3 } \cline { 6 - 6 } & Mean (SD) & Range & & Mean (SD) & Range \\
\hline Age (yr) & $21.56(2.13)$ & $18-26$ & & $75.91(4.77)$ & $65-85$ \\
Education (yr) & $13.58(1.29)$ & $11-16$ & & $13.00(1.88)$ & $12-18$ \\
Gender (male:female) & $11: 34$ & & & $14: 31$ & \\
K-MMSE & $29.33(.85)$ & $28-30$ & & $28.98(1.01)$ & $27-30$ \\
STAND & $29.93(.25)$ & $29-30$ & & $29.82(.44)$ & $28-30$ \\
\hline
\end{tabular}

K-MMSE = Korean version of Mini-Mental State Examination (Kang, Na, \& Hahn, 1997); STAND = Screening Test for Aphasia Neurologic Communication Disorders (Kim, Hoe, Kim, \& Kim, 2009).

Likert 5점 척도로 표기하도록 하였다. 여기서 최상위점을 받은 단 어를 상위친숙도 범주, 최하위점을 받은 단어를 하위친숙도 범주로 구분하였다. 최종적으로는 언어병리학 박사학위소지자 1 명과 제 1 저자가 함께 각 품사 당 상위빈도이면서 상위친숙도에 해당하는 단 어 6개, 하위빈도이면서 하위친숙도에 해당하는 단어 6개씩 최종 36 개의 단어를 최종 선정하였다( 12 개 단어 $\times 3$ 품사). 명사의 경우 는 사람이나 사물을 지칭하는 시각적인 참조물이 있는 구체명사와 구체적인 실체가 없는 추상명사의 특성이 같지 않으므로 각각 상위 빈도 및 친숙도에 속하는 단어 3개, 하위빈도 및 친숙도에 속하는 단어 3 개씩으로 구성되었다. 검사 단어는 Appendix 1에 제시하였다.

\section{연구 절차}

정상 성인의 정의하기 검사는 소음이 없는 조용한 장소에서 연구 자와 대상자가 일대일로 진행하였다. 대상자의 반응과 검사자의 지 시는 모두 삼성 캠코더와 녹음기로 녹음하였고, 본 연구자가 정의 반응을 직접 듣고 실시간 전사한 후 녹화된 동영상으로 대상자의 반응을 다시 한 번 확인하였다. 검사 절차는 먼저 대상자에게 지시 문을 들려주면서 예시와 함께 검사의 방법을 설명한 후, 품사 무작 위 순으로 검사 단어를 제시하였다. 검사의 단어는 한 단어씩 A4용 지에 인쇄되었으며 이를 시각적으로 제시하면서 “ 가 무엇입 니까? 이것을 설명해보세요”라고 청각적으로 들려주었다. 대상자의 반응이 없는 경우에는 "다른 사람에게 의 뜻을 설명해줘야 한 다면 뭐라고 하면 그 사람이 이해할 수 있을까요?” 혹은 “___ 가 무슨 뜻인지 아는 것을 모두 말해줄래요?” 라고 질문하여 반응을 촉진하였다(Johnson \& Anglin, 1995; Park, 2005). 수행 시에 정의 하기 반응을 준비하는 시간이 결과에 미치는 영향을 배제하기 위 하여 자료 분석 시에는 대상자의 각 단어의 정의하기 과제마다 30 초 이내에 발화가 시작된 경우만 선택하여 분석하였다. 본 연구의 모든 연구 절차는 한림대학교 연구윤리위원회(IRB)의 승인(HIRB2015-054)을 받았다.

\section{자료 분석}

정의하기 점수의 채점 기준

채점 기준은 국내 선행연구 중 정의 반응의 채점기준을 주요 특 성(단어의 속성)과 상위어, 부수적 특징으로 점수를 나눈 Park과 Kim (2000), Lim (2010), Kim과 Choi (2012), Kim (2015)의 채점기 준을 참고하여 수정 및 보완하였다. 정의 점수는 총 72점(36문항 $\times$ 2점) 만점이었고, 채점기준에서 주요 특성은 국립국어원 표준국어 대사전(National Institute of Korean Language, 2015)의 사전적 정 의를 참고하여 기준으로 하였다. 정의 점수의 분석기준은 Appendixes 2-4에 요약하여 제시하였다.

\section{정의 유형에 대한 분류기준}

선행연구(Park \& Kim, 2000; Park, 2005; Lim, 2010; Jang, 2012; J. H. Kim, 2014)의 정의 유형 분류를 수정 및 보완하였다. 대상자가 하나의 검사 낱말에 대해 두 가지 이상의 유형으로 답하였을 경우 에는 각각을 유형별 분석에 포함시켰다. 정의 유형 중 구체명사는 Appendix 5, 추상명사, 동사, 형용사는 Appendix 6에 제시하였다. 여기서 기타는 기능적, 지각적, 관계적, 분류적, 특징적 정의에 해당 하지 않는 오류 반응으로서, 그 오류 유형에 따라 바로 다음에 제시 되는 기준과 같이 분류하였다.

\section{오류유형에 대한 분류기준}

오류유형은 정의 유형에서 기타의 반응만을 대상으로 하였고 Park (2005)과 Kim J. H. (2014)의 정의 유형에서 기타 유형을 참고 하였으며, $\operatorname{Lim}$ (2010)의 오류 유형을 바탕으로 수정, 보완하였다. 오 류유형은 Appendix 7에 제시하였다.

\section{반응시간}

반응시간(response time)은 검사자가 검사 단어를 청각적으로 “___가 무엇입니까? 이것의 뜻이 무엇인지 설명해보세요”라고 지시한 마지막 음절이 끝난 시점부터 대상자가 정의하기를 위해 발 화의 첫 음절을 개시하기 전까지 소요된 시간을 Computerized Speech Lab을 사용하여 ms (1/1,000초) 단위로 분석하였다

\section{신뢰도}

자료 분석에 대한 신뢰도를 검증하기 위해 언어병리학을 전공한 석사학위소지자 2 명에게 검사 방법과 채점, 분석 방법에 대해 상세 히 설명한 후, 전체 자료의 $10 \%$ 을 무작위로 추출하여 분석하도록 하였다. 신뢰도는 연구자와 평가자가 일치한 반응의 수를 일치한 반응의 수와 불일치한 반응의 수를 더한 수로 나누고 100 을 곱하 
여 산출하였다. 연구자와 제 1 평가자의 검사자 간 신뢰도는 정의 점 수 96.83\%, 정의 유형 94.97\%, 오류 유형 93.28\%로 나타났으며 연 구자와 제 2 평가자의 검사자 간 신뢰도는 정의 점수 $90.15 \%$, 정의 유 형 92.65\%, 오류 유형 90.30\%로 나타났다. 제 1 평가자와 제 2 평가자 의 검사자 간 신뢰도는 정의 점수 $93.10 \%$, 정의 유형 $97.55 \%$, 오류 유형 $96.80 \%$ 로 나타났다.

\section{자료의 통계처리}

본 연구에서는 SPSS ver. 22를 활용하여 집단 간 품사에 따른 정의 점수, 반응시간의 차이를 반복측정 분산분석(repeated measures ANOVA)으로 비교하였다. 반복측정 분산분석에서 사후분석으로 집단 내를 대응표본 $t$-test로 실시하였다. 집단 간 품사별 정의 유형 과 오류유형의 비율에 대한 비교는 독립표본 $t$-test를 실시하였다.

\section{연구 결과}

\section{연령 집단과 품사에 따른 정의 점수 차이}

노년층은 청년층보다 명사 $(p<.001)$, 동사 $(p<.001)$, 형용사 $(p<$ .001), 총 점수 $(p<.001)$ 모든 품사의 정의 점수에서 유의미하게 낮은 점수를 보였다. 이에 대한 기술 통계 결과는 아래 Table 2 와같다. 연령 집단에서 품사별 점수빈도 결과는 Appendixes 8-10에 제시하였다.

연령 집단과 품사에 따른 정의 점수 차이를 비교하기 위해 반복

Table 2. Definition scores by age groups

\begin{tabular}{lcrc}
\hline Group & Young group & Elderly group & \multicolumn{1}{c}{$t$} \\
\hline Nouns & $13.76(4.91)$ & $7.98(3.62)$ & $-6.430^{* * *}$ \\
Verbs & $11.84(4.13)$ & $7.11(4.10)$ & $-5.459^{* * *}$ \\
Adjectives & $12.78(3.29)$ & $7.80(2.71)$ & $-7.230^{* * *}$ \\
Total score & $38.38(10.89)$ & $22.89(9.14)$ & $-7.173^{* * *}$ \\
\hline
\end{tabular}

Values are presented as mean (SD).

${ }^{* * *} p<.001$.

Table 3. Repeated measurement ANOVA results: definition scores by age groups and word class

\begin{tabular}{lrrrr}
\hline & $\begin{array}{c}\text { Type III sum of } \\
\text { squares }\end{array}$ & df & Mean square & $F$ \\
\hline Between & & & & \\
$\quad$ Age & $5,397.878$ & 1 & $5,397.878$ & $53.402^{* * *}$ \\
$\quad$ Error & $8,895.022$ & 88 & 101.080 & \\
Within & & & & \\
$\quad$ Word class & $28,239.656$ & 1.583 & $17,835.625$ & $632.882^{* * *}$ \\
$\quad$ Word class*Age & $1,812.722$ & 1.583 & $1,144.881$ & $40.625^{* * *}$ \\
$\quad$ Error & $3,926.622$ & 139.333 & 28.182 & \\
\hline
\end{tabular}

${ }^{* * *} p<.001$.
측정 분산분석(repeated measures ANOVA)으로 확인한 결과, 연령 집단과 품사의 정의 점수 간에 상호작용이 관찰되었다 $(F=40.625$, $p<.001)$. 연령에 따른 품사의 정의 점수는 노년층이 청년층 보다 유 의미하게 낮은 점수를 보였다 $(F=53.402, p<.001)$. 품사에 따른 정 의 점수에서도 유의미한 차이가 있었다 $(F=632.882, p<.001)$. 이 에 대한 통계분석 결과는 아래 Table 3과 같다.

상호작용 효과의 원인을 살펴보기 위해 사후검증 시 품사를 대 응표본 $t$-test로 실시하였다. 품사별 정의 점수를 비교한 결과, 명사 가 동사 $(t=3.635, p<.001)$ 보다 유의미하게 높은 점수를 보였고 형 용사가 동사 $(t=-2.490, p=.015)$ 보다 유의미하게 높은 점수를 보였 다. 이에 대한 상호작용 효과는 Figure 1과 같다.

\section{연령 집단 간의 정의 유형 차이}

구체명사의 정의 유형 차이

연령 집단 간 구체명사의 정의 유형을 비교하기 위해 독립표본 $t$ test로 통계 분석한 결과, 구체명사에서 노년층은 청년층보다 기능 적 $(t=3.915, p<.001)$ 으로 더 많이 정의하였으며 분류적 $(t=-2.541$, $p=.013)$ 으로는 더 적게 정의하는 경향을 보였다. 이에 대한 통계분 석 결과는 아래 Table 4 와 같다.

\section{추상명사의 정의 유형 차이}

연령 집단 간 추상명사의 정의 유형을 비교하기 위해 독립표본 $t$ -

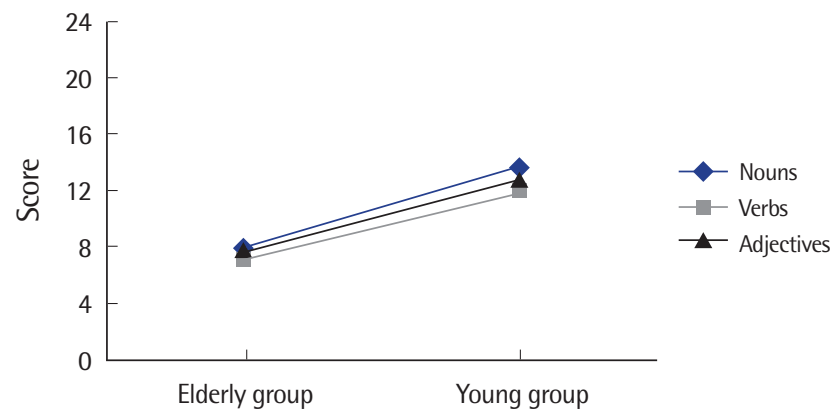

Figure 1. Interaction effect on definition scores by age groups and word class.

Table 4. Ratio of definition types in concrete nouns by age group

\begin{tabular}{lccc}
\hline Concrete nouns & Young group & Elderly group & $t$ \\
\hline Function & $1.31(22.38)$ & $1.49(43.45)$ & $3.915^{* * *}$ \\
Perception & $2.76(48.14)$ & $1.49(39.05)$ & -1.610 \\
Relation & $.64(11.55)$ & $.36(9.25)$ & -.559 \\
Category & $1.11(17.93)$ & $.36(8.25)$ & $-2.541^{*}$ \\
\hline
\end{tabular}

Values are presented as mean (\%).

${ }^{*} p<.05,{ }^{* * *} p<.001$. 
Table 5. Ratio of definition types in abstract nouns by age group

\begin{tabular}{lccc}
\hline Abstract nouns & Young group & Elderly group & $t$ \\
\hline Relation & $3.00(58.93)$ & $2.78(71.33)$ & $2.090^{*}$ \\
Category & $1.60(31.37)$ & $.33(9.05)$ & $-4.374^{* * *}$ \\
Feature & $.51(9.70)$ & $.78(19.62)$ & $2.138^{*}$ \\
\hline
\end{tabular}

Values are presented as mean (\%).

${ }^{*} p<.05,{ }^{* * *} p<.001$.

Table 6. Ratio of definition types in verbs by age group

\begin{tabular}{lccc}
\hline Verbs & Young group & Elderly group & $t$ \\
\hline Relation & $6.49(64.17)$ & $5.38(77.26)$ & $2.916^{* *}$ \\
Category & $1.84(17.51)$ & $1.13(13.10)$ & -1.137 \\
Feature & $1.98(18.32)$ & $.69(9.63)$ & $-3.061^{* *}$ \\
\hline
\end{tabular}

Values are presented as mean (\%).

${ }^{* *} p<.01$.

Table 7. Ratio of definition types in adjectives by age group

\begin{tabular}{lccc}
\hline Adjectives & Young group & Elderly group & $t$ \\
\hline Relation & $7.98(73.56)$ & $6.36(84.57)$ & $2.921^{* *}$ \\
Category & $1.13(11.12)$ & $.87(11.89)$ & .257 \\
Feature & $1.69(15.32)$ & $.29(3.54)$ & $-5.445^{* * *}$ \\
\hline
\end{tabular}

Values are presented as mean (\%).

${ }^{* *} p<.01,{ }^{* * *} p<.001$.

test로 통계 분석한 결과, 추상명사에서 노년층은 청년층 보다 관계 적 $(t=2.090, p=.04)$, 특징적 $(t=2.138, p=.035)$ 으로 더 많이 정의하 였으며, 분류적 $(t=-4.374, p<.001)$ 으로 적게 정의하는 경향을 보였 다. 이에 대한 통계분석 결과는 아래 Table 5와같다.

\section{동사의 정의 유형 차이}

연령 집단 간 동사의 정의 유형을 비교하기 위해 독립표본 $t$-test 로 통계 분석한 결과, 동사에서 노년층은 청년층보다 관계적 $(t=2.916$, $p=.005)$ 으로 더 많이 정의하고, 특징적 $(t=-3.061, p=.003)$ 으로는 더 적게 정의하는 경향을 보였다. 이에 대한 통계분석 결과는 아래 Table 6과 같다.

\section{형용사의 정의 유형 차이}

연령 집단 간 형용사의 정의 유형을 비교하기 위해 독립표본 $t$ test로 통계 분석한 결과, 형용사에서 노년층은 청년층보다 관계적 $(t=2.921, p=.004)$ 으로 더 많이 정의하고, 특징적 $(t=5.445, p<.001)$ 으로 더 적게 정의하는 경향을 보였다. 이에 대한 통계분석 결과는 아래 Table 7과 같다.
Table 8. Ratio of errors types in concrete nouns by age group

\begin{tabular}{lccc}
\hline Concrete nouns & Young group & Elderly group & $t$ \\
\hline Non-adequate definition & $.13(27.08)$ & $.11(10.48)$ & -1.573 \\
Repetition of target vocabulary & $.0(.0)$ & $1.11(57.62)$ & $3.236^{* *}$ \\
Individual response & $.29(66.67)$ & $.38(15.71)$ & $-4.622^{* * *}$ \\
Gestures & $.0(.0)$ & $.62(24.29)$ & $2.218^{*}$ \\
No response & $.02(6.25)$ & $.05(4.55)$ & -.240 \\
\hline
\end{tabular}

Values are presented as frequency $(\%)$.

${ }^{*} p<.05,{ }^{* *} p<.01,{ }^{* * *} p<.001$.

Table 9. Ratio of errors types in abstract nouns by age group

\begin{tabular}{lccc}
\hline Abstract nouns & Young group & Elderly group & $t$ \\
\hline Non-adequate definition & $.40(43.75)$ & $.69(36.85)$ & -.590 \\
Repetition of target vocabulary & $.16(23.33)$ & $.87(37.30)$ & 1.361 \\
Individual response & $.31(32.92)$ & $.49(19.91)$ & -1.525 \\
Gestures & $.0(.0)$ & $.02(.90)$ & 1.000 \\
No response & $.0(.0)$ & $.09(5.05)$ & 1.247 \\
\hline
\end{tabular}

Values are presented as mean (\%).

\section{연령 집단 간의 정의하기 오류유형 차이}

구체명사의 오류 유형 차이

연령 집단 간 구체명사의 오류 유형을 비교하기 위해 독립표본 $t$ test로 통계 분석한 결과, 구체명사에서 노년층은 청년층보다 목표 어휘반복 $(t=3.236, p=.002)$, 제스처 $(t=2.218, p=.031)$ 를 더 많이 보였으며 개인적 반응 $(t=-4.622, p<.001)$ 은 더 적었다. 이에 대한 통계분석 결과는 아래 Table 8 과 같다.

\section{추상명사의 오류 유형 차이}

연령 집단 간 추상명사의 오류 유형을 비교하기 위해 독립표본 $t$ test로 통계 분석한 결과, 추상명사에서 노년층은 청년층과 오류유 형에서 유의미한 차이가 관찰되지 않았다 $(p>.05)$. 이에 대한 통계 분석 결과는 아래 Table 9와같다.

\section{동사의 오류 유형 차이}

연령 집단 간 동사의 오류 유형을 비교하기 위해 독립표본 $t$-test 로 통계 분석한 결과, 동사에서 노년층은 청년층보다 목표어휘반복 $(t=3.574, p=.001)$, 제스처 $(t=2.155, p=.035)$ 를 더 많이 보였고, 불 충분한 정의 $(t=-3.115, p=.003)$ 는 더 적었다. 이에 대한 통계분석 결과는 아래 Table 10과같다.

\section{형용사의 오류 유형 차이}

연령 집단 간 동사의 오류 유형을 비교하기 위해 독립표본 $t$-test 로 통계 분석한 결과, 형용사에서 노년층은 청년층보다 목표어휘반 
Table 10. Ratio of errors types in verbs by age group

\begin{tabular}{lccc}
\hline Verbs & Young group & Elderly group & $t$ \\
\hline Non-adequate definition & $.49(39.45)$ & $.49(12.91)$ & $-3.115^{* *}$ \\
Repetition of target vocabulary & $.91(30.32)$ & $3.49(63.93)$ & $3.574^{* *}$ \\
Individual response & $.29(23.26)$ & $.56(11.92)$ & -1.533 \\
Gestures & $.0(.0)$ & $.18(4.78)$ & $2.155^{*}$ \\
No response & $.07(6.82)$ & $.13(6.46)$ & -.065 \\
\hline
\end{tabular}

Values are presented as mean (\%).

${ }^{*} p<.05,{ }^{* *} p<.01$.

Table 11. Ratio of errors types in adjectives by age group

\begin{tabular}{lccc}
\hline Adjectives & Young group & Elderly group & $t$ \\
\hline Non-adequate definition & $.42(35.00)$ & $.49(17.85)$ & -1.966 \\
Repetition of target vocabulary & $.31(20.56)$ & $2.51(52.40)$ & $3.483^{* *}$ \\
Individual response & $.38(36.11)$ & $1.07(22.16)$ & -1.603 \\
Gestures & $.0(.0)$ & $.07(2.71)$ & 1.349 \\
No response & $.09(6.67)$ & $.13(6.10)$ & -.097 \\
\hline
\end{tabular}

Values are presented as mean (\%).

${ }^{* *} p<.01$.

Table 12. Definition response times (ms) by age group

\begin{tabular}{llcl}
\hline Group & \multicolumn{1}{c}{ Young group } & \multicolumn{1}{c}{ Elderly group } & \multicolumn{1}{c}{$t$} \\
\hline Concrete nouns & $1,358.89(709.36)$ & $2,480.44(1,126.97)$ & $5.650^{* * *}$ \\
Abstract nouns & $2,587.56(1,714.58)$ & $3,140.89(1,306.40)$ & 1.722 \\
Verbs & $2,099.56(1,138.81)$ & $2,880.22(1,199.50)$ & $3.166^{* *}$ \\
Adjectives & $2,235.33(1,650.75)$ & $3,051.11(1,499.40)$ & $2.454^{*}$ \\
Total response times & $8,778.22(6,265.26)$ & $11,552.67(4,136.98)$ & $2.479^{*}$
\end{tabular}

Values are presented as mean (SD).

${ }^{*} p<.05,{ }^{* *} p<.01,{ }^{* * *} p<.001$.

복 $(t=3.483, p=.001)$ 을 더 많이 보였다. 이에 대한 통계분석 결과는 Table 11과 같다.

\section{연령 집단과 품사에 따른 정의하기의 반응시간 차이}

노년층은 청년층보다 구체명사 $(p<.001)$, 동사 $(p=.002)$, 형용사 ( $p=.016)$, 품사 전체의 총 반응시간 $(p=.015)$ 이 유의미하게 길었고, 추상명사의 반응시간에서는 연령 집단 간 유의미한 차이가 없었 다. 이에 대한 기술 통계 결과는 Table 12 와 같다.

연령 집단과 품사에 따른 정의하기의 반응시간 차이를 비교하기 위해 반복측정 분산분석(repeated measures ANOVA)으로 확인 한 결과, 연령 집단과 품사에 따른 반응시간에서 상호작용이 나타 났다 $(F=4.014, p=.036)$. 연령에 따른 품사의 반응시간은 노년층이 청년층보다 유의하게 길었고 $(F=9.582, p=.003)$. 품사에 따른 반응 시간에서 유의미한 차이가 있었다 $(F=237.661, p<.001)$. 이에 대한 통계분석 결과는 Table 13과 같다.
Table 13. Repeated measures ANOVA results: definition response times by age groups and word class

\begin{tabular}{lrrrr}
\hline & \multicolumn{1}{c}{$\begin{array}{c}\text { Type III sum of } \\
\text { squares }\end{array}$} & df & Mean square & $F$ \\
\hline Between & & & & \\
Age & $164,481,430.222$ & 1 & $164,481,430.222$ & $9.582^{* *}$ \\
Error & $1,510,584,662.222$ & 88 & $17,165,734.798$ & \\
Within & & & & \\
$\quad$ Word class & $4,297,536,470.222$ & 1.343 & $3,200,673,402.416$ & $237.661^{* * *}$ \\
Word class $\times$ Age & $72,590,729.778$ & 1.343 & $54,063,349.938$ & $4.014^{*}$ \\
Error & $1,591,268,960.000$ & 118.157 & $13,467,367.429$ & \\
\hline
\end{tabular}

${ }^{*} p<.05,{ }^{* *} p<.01,{ }^{* * *} p<.001$.

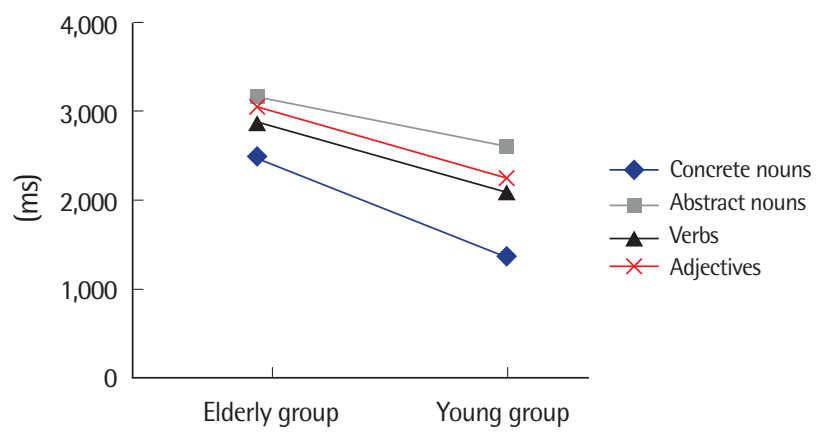

Figure 2. Interaction effect on definition response times by age groups and word class.

상호작용 효과의 원인을 살펴보기 위해 사후검증 시 품사를 대응 표본 $t$-test로 실시하였다. 품사별로 반응시간 차이를 확인한 결과 구체명사 정의하기에서의 반응시간이 추상명사 $(t=-6.237, p<.001)$, 동사 $(t=-4.830, p<.001)$, 형용사 $(t=-4.618, p<.001)$ 보다 더 짧았 다. 또한 동사 정의하기에서의 반응시간이 추상명사에서보다 더 짧 았다 $(t=2.549, p=.013)$. 이에 대한 상호작용 효과는 Figure 2와같다.

\section{논의 및 결론}

연령 집단 간 품사별 정의하기 점수를 비교한 결과, 노년층은 모 든 품사에서 청년층보다 낮은 수행력을 보였다. 수행의 양상을 살 펴보면, 명사에서 청년 집단은 단어의 정확한 속성과 함께 분류적 인 정의를 하며, 한가지의 개념으로만 설명하지 않고 단어가 가지고 있는 속성과 함께 분류적 정의를 결합하거나 해당 단어에 대한 정 확한 내용을 2 개 이상 설명하여 양적, 질적으로 풍부하고 구체적으 로 정의하였다. 그러나 노인 집단은 주로 상황적 맥락과 관련하여 정의하거나(예: 물-목마를 때) 기능적, 지각적, 검사 단어와 연관된 다른 단어로 정의하는 경향이 빈번하였다. 반면 동사, 형용사에서 는 노인이 상황적 맥락으로 표현하거나 관련된 다른 단어로 정의하 
는 경향이 있었다. 정의하기를 올바르게 수행하기 위해서는 의미기 억과 어휘 사전으로의 접근이 용이해야 하며, 단어를 여러 개념들 과 의미적으로 연결하여 조직화해야 하는데, 노년층은 이러한 과정 에서 단어가 가진 의미를 적절하고 다양하게 표현하는데 제한이 있는 것을 의미한다. 이는 명사에서 노년층의 정의하기 능력이 저하 된다는 선행연구(Kim \& Choi, 2012)의 결과를 지지함과 동시에 동 사와 형용사 또한 노화에 영향을 받는 것으로 해석할 수 있다. 집단 간 교육년수의 차이가 정의하기의 수행력에 영향 줄 수 있으나(Botwinick, West, \& Storandt, 1975; Kim \& Choi, 2012), 본 연구에서 는 연령 집단 간 교육년수 차이가 나지 않았음에도 불구하고 연령 에 따라 수행력의 저하가 관찰되었다는 것이 의미가 있다. 연령 집 단에 따른 품사간수행력을 확인하였을 때, 두 집단 모두 명사의 정 의 점수가 동사의 정의 점수보다 더 높았다. 이러한 이유로는 동사 보다 명사가 의미면에서 더 단순하고 단정적인 특징을 가지고 있기 때문에(Johnson \& Anglin, 1995) 단어에 대한 개념을 표상하기 쉬 워서 많은 의미적 정보를 표현한 것으로 볼 수 있다.

연령에 따른 품사별 정의하기 특성을 확인하기 위하여 노년층과 청년층의 품사별 정의 유형을 살펴본 결과, 구체명사에서 노인 집단 은 제시되는 단어에 대하여 기능적인 측면인 사용 용도에 초점을 맞추어 더 많이 정의하였고, 상위어 등으로 정의하는 분류적 정의 유형은 가장 비율이 낮았으며, 청년에 비해서도 그 비율이 유의미 하게 낮았다. 이는 상위어를 통하여 정의하기 위해서는 시각화하기 쉬운 단어 자체에 대한 의미 지식뿐만 아니라 해당 단어와 의미적 으로 자질을 공유하거나 연결되는 다른 단어와의 의미망(semantic networks)을 파악하고, 그 위계를 형상화 하는 능력이 필요하므로 보다 발전된 정의하기로 간주된다(Benelli, Arcuri, \& Marchesini, 1988). 따라서 이러한 결과는 노인이 구체명사에서 상위어 산출에 필요한 의미망의 다각적인 활성화보다는 좀더 기본적인 단계에서 해당 단어에 대한 기능적 의미지식을 사용하여 정의하는 것을 더 욱 선호하는 것으로 해석할 수 있겠다. 반면에 추상명사와 동사, 형 용사에서는 노인이 청년보다 관계적으로 정의하는 양상을 보였다. 이러한 결과는 추상명사와 동사, 형용사에서 노인이 단어의 속성 이나 정확한 의미보다는 관련된 상황, 사물, 조건 등을 단어와 관련 시켜 정의하는 것으로 볼 수 있다.

기타로 분류되었던 오류의 유형을 살펴본 결과, 노인 집단은 구 체명사, 동사, 형용사에서 노인이 청년보다 제시된 목표 어휘를 그 대로 사용하여 반복하거나 목표 단어에 상응하는 제스처(몸짓)로 반응하는 경향을 더 많이 보였다. 이는 노화 과정에서 구어적 다양 성에 제약이 생겨 새롭고 다양한 단어를 연상하고 생성하는 것에 서의 어려움에 기인한 것일 수 있으며(Kemper, Thompson, \& Mar- quis, 2001), 결과적으로는 의사소통 상황에서 특정 의미를 설명할 때 구어적 내용부족과 전달 오류 등으로 이어질 수 있다. 따라서 노 인들은 의사소통의 효용성을 보완하는 측면에서 구어를 대체할 수 있는 제스처를 사용하게 되는 것으로 보인다. 선행연구(Lim, 2010) 에서는 통제군으로 포함된 정상 노인들이 정의하기 시에 목표 어휘 의 반복이나 제스처를 전혀 보이지 않아서 본 연구 결과와는 다른 결과를 보여주나 이러한 차이는 검사어휘가 추출된 문헌의 차이에 기인하는 것으로 생각된다. 선행연구 $(\operatorname{Lim}, 2010)$ 의 경우 알츠하이 머성 치매 환자의 정의하기 특징을 살펴보는 것이 주 목적이었으므 로 과제의 원활한 수행을 위해 고빈도 어휘 중에서 국어교육용 어 휘(Kim, 2003b) 중 1등급(기초어휘)에 해당하는 구체명사(예: 칫솔, 당근, 호랑이)만을 사용하였다. Kim (2003a)은 이 기초어휘들이 학 령기 이전의 아동들이 이미 학습한 단어의 수준에 해당한다고 명 시하고 있으며, 8-36개월 아동의 어휘를 검사하는 한국판 맥아더베이츠 의사소통발달 평가(Pae \& Kwak, 2007)에서 제시하는 어휘 목록에 속한다. 따라서 선행연구의 어휘는 정상 노인에게는 상대적 으로 정의하기가 쉬운 구체적인 명사였기 때문에 제스처 등이 사용 되지 않았을 가능성이 있다. 반면에 본 연구에서 제시한 검사어휘 는 신문, 책 등의 문헌 조사를 통한 어휘집(Kang \& Kim, 2009)을 기초로 하여 추출된 어휘였기 때문에 비록 200 빈도까지의 고빈도 순위 내에서 추출되었다 할지라도 검사 어휘에 시각적 참조물이 없 는 추상 명사(예: 삶, 전쟁, 정보, 사실, 방법)가 포함되어 있었다. 또 한 수용·표현어휘력검사(Receptive \& Expressive Vocabulary Test, REVT; Kim, Hong, Kim, Jang, \& Lee, 2009)에 근거해볼 때 학령기 이후에 학습될 수 있는 단어가 포함되었을 가능성이 있다. 따라서 본 연구의 노인 집단은 보다 어려운 수준의 개념을 정의하면서 수 반될 수 있는 내용 부족 등의 결함을 보완하는 측면에서 제스처 등 이사용하였을 가능성이 있겠다.

마지막으로, 연령에 따른 품사별 정의하기의 반응시간을 살펴본 결과, 노인 집단은 정의하기를 개시할 때까지 청년 집단 보다 더 많 은 시간이 필요하였다. 정의하기를 개시하기 위해서는 의미 어휘사 전으로의 접근과 더불어 정보를 조직화하고 단어를 인출하는 과정 이 필요한데 이는 각각 인지언어적 활동에 기반이 되는 측두엽과 전두엽의 기능으로 알려져 있다(Aine et al., 2011; Chow et al., 2008). 그러나 노화에 따른 전두엽과 측두엽의 기능 자체의 감퇴와 더불 어 연령이 증가함에 따라 의미망으로 접근하거나 활성화하는 속도 가 지연되는 것(Abraham et al., 2012)으로도 반응 속도의 지연을 해석해 볼 수 있다. 정보의 접근이나 활성화를 담당하는 것은 신경 망 내의 전달과정과 관련이 있는데, 특히 노화에 따라 단어 인출을 담당하는 전전두엽(prefrontal lobe)영역과 연결되는 백질(white 
matter)의 신경생리적 변화가 보고되고 있고(Kanchibhotla et al., 2013), 정의하기와 같이 전전두엽의 확산적 사고(divergent thinking) 기능을 필요로 하는 과제의 경우에는 노화의 영향을 더 많이 받게 되므로(Abraham et al., 2012), 이러한 신경생리적 변화가 반 응 개시 시간에 반영되었을 수 있다. 흥미로운 점은 추상명사의 경 우 오류 유형이나 반응시간의 측면에서 연령에 따른 차이가 관찰되 지 않았다. 구체명사와는 대조적으로 추상명사는 해당 단어에 대 한 시각적 참조물이 존재하지 않으므로 단어의 개념을 정확하고 명료하게 표상하여 정의하는 것에서 청년과 노년 모두 어려움을 보 였음을 유추해볼수 있다.

본 연구에서는 명사, 동사, 형용사 정의하기 과제를 통하여 정상 노화에 따른 노인의 의미 어휘처리 과정의 특성을 관찰하였으며 이는 노화에 따른 정상적인 언어 능력의 변화에 대한 연구 시 기초 자료로 사용될 수 있겠다. 또한 다양한 품사로 이루어진 정의하기 과제가 의미 어휘영역의 평가 및 중재 시에 유용한 과제로 사용될 수 있으며, 품사의 특성을 반영한 0-2점 척도로 이루어진 간소화된 분석방법을 통하여 임상 상황에서 연령에 따른 정의하기 능력의 차이를 효율적으로 감별할 수 있는 근거를 제시하였다. 마지막으로 오류 유형 분석을 통하여 정의하기 시에 저하된 노인들은 구어적 의미 어휘능력의 감퇴를 보완하기 위하여 제스처의 수단을 사용함 을 관찰하였다.

서론에서 언급하였듯이 의미 어휘능력의 발달은 생애에 걸쳐 지 속적으로 이루어지는데 18개월부터 6세까지 하루 평균 9-10개의 새로운 어휘를 습득하며, 약 10세가 되면 1년에 약 5-6천 개씩 새로 운 단어를 습득한다(Choi, 2001). 청년기에도 새로운 약 45,00050,000 여 새로운 어휘를 습득하면서 의미망을 점차 확대하게 된다 (Choi, 2001). 따라서 추후 연구에서는 의미 어휘능력의 전 생애적 인 발달과 퇴화의 관점에서 청년층 이후에 장년층, 노년층으로 이 어지는 정의하기 능력의 변화를 관찰하는 것도 중요하겠다. 검사 단어 선정 측면에서의 본 연구의 제한점은 참고문헌(Kang \& Kim, 2009)에서 200순위까지의 어휘를 선택하였으므로 고빈도나 중빈 도의 단어가 비교적 많이 포함되었을 가능성이 있다. 추후 연구에 서는 검사 단어 선정 시 저빈도나 난이도가 높은 단어 등을 사용하 여 단어 빈도에 따른 정의하기 능력을 살펴보는 것이 필요하겠다.

\section{REFERENCES}

Abraham, A., Pieritz, K., Thybusch, K., Rutter, B., Kröger, S., Schweckendiek, J., ..., \& Hermann, C. (2012). Creativity and the brain: uncovering the neural signature of conceptual expansion. Neuropsychologia, 50, 1906-1917.
Aine, C. J., Sanfratello, L., Adair, J. C., Knoefel, J. E., Caprihan, A., \& Stephen, J. M. (2011). Development and decline of memory functions in normal, pathological and healthy successful aging. Brain Topography, 24, 323-339.

Astell, A. J., \& Harley, T. A. (2002). Accessing semantic knowledge in dementia: evidence from a word definition task. Brain and Language, 82, 312-326.

Barresi, B. A., Nicholas, M., Tabor Connor, L., Obler, L. K., \& Albert, M. L. (2000). Semantic degradation and lexical access in age-related naming failures. Aging, Neuropsychology, and Cognition, 7, 169-178.

Benelli, B., Arcuri, L., \& Marchesini, G. (1988). Cognitive and linguistic factors in the development of word definitions. Journal of Child Language, 15, 619-635.

Bierwisch, M., \& Kiefer, F. (1969). Remarks on definitions in natural language. In F. Kiefer (Ed.), Studies in syntax and semantics (pp. 55-79). Dordrecht: Springer Netherlands.

Botwinick, J., West, R., \& Storandt, M. (1975). Qualitative vocabulary test responses and age. Journal of Gerontology, 30, 574-577.

Bowers, L., Huisingh, R., LoGiudice, C., \& Orman, J. (2004). The Word Test 2 Elementary by LinguiSystems. Austin, TX: Pro-Ed.

Choi, J. Y. (2001). A study on the vocabulary of middle school Korean textbooks (Master's thesis). Keimyng University, Daegu, Korea.

Chow, T. W., Binns, M. A., Freedman, M., Stuss, D. T., Ramirez, J., Scott, C. J., \& Black, S. (2008). Overlap in frontotemporal atrophy between normal aging and patients with frontotemporal dementias. Alzheimer Disease \& Associated Disorders, 22, 327-335.

Christensen, K. J., Multhaup, K. S., Nordstrom, S., \& Voss, K. (1991). A cognitive battery for dementia: development and measurement characteristics. Psychological Assessment: A Journal of Consulting and Clinical Psychology, 3(2), 168-174.

Cutting, J. C., \& Ferreira, V. S. (1999). Semantic and phonological information flow in the production lexicon. Journal of Experimental Psychology: Learning, Memory, and Cognition, 25, 318-344.

Hodges, J. R., Patterson, K., Graham, N., \& Dawson, K. (1996). Naming and knowing in dementia of Alzheimer's type. Brain and Language, 54, 302-325. Jang, H. J. (2012). Comparison of verbal defining of concrete and abstract nouns between ADHD children and normal children (Master's thesis). Yongin University, Yongin, Korea.

Johnson, C. J., \& Anglin, J. M. (1995). Qualitative developments in the content and form of children's definitions. Journal of Speech, Language, and Hearing Research, 38, 612-629.

Kanchibhotla, S. C., Mather, K. A., Wen, W., Schofield, P. R., Kwok, J. B., \& 
Sachdev, P. S. (2013). Genetics of ageing-related changes in brain white matter integrity: a review. Ageing Research Reviews, 12, 391-401.

Kang, B. M., \& Kim, H. K. (2004). Frequency analysis of Korean morpheme and word usage 2. Seoul: Korea University, Research Institute of Korea Studies.

Kang, B. M., \& Kim, H. K. (2009). Frequency of Korean. Seoul: Hankookmunhwasa.

Kang, Y., Na, D. L., \& Hahn, S. (1997). Korean version of Mini-Mental State Examination (K-MMSE). Seoul: Human Brain Research \& Consulting Co.

Kemper, S., Thompson, M., \& Marquis, J. (2001). Longitudinal change in language production: effects of aging and dementia on grammatical complexity and propositional content. Psychology and Aging, 16, 600-614.

Kim, H., Hoe, J. H., Kim, D. Y., \& Kim, J. W. (2009). Screening test for aphasia neurologic communication disorders. Seoul: Hakjisa.

Kim, J. H. (2014). The definition development of nouns, verbs, adjectives for persons with hearing impairment (Master's thesis). Daegu University, Gyeongsan, Korea.

Kim, K. H. (2003a). Concept and importance of basic vocabulary. New Korean Life, 13, 5-29.

Kim, K. H. (2003b). Korean vocabulary. Seoul: Pagijung.

Kim, M. B. (2014). A Korean literature review of metalinguistic skills in semantics and grammar. Journal of Speech-Language \& Hearing Disorders, 23, 61-77.

Kim, S. J., \& Choi, H. (2012). Characteristics of verbal definitions in normal elderly Koreans. Korean Journal of Communication Disorders, 17, 107-117.

Kim, S. R. (2015). Abstract word definition in patients with amnestic mild cognitive impairment (Doctoral dissertation). Yonsei University, Seoul, Korea.

Kim, Y. T., Hong, G. H., Kim, K. H., Jang, H. S., \& Lee, J. Y. (2009). Receptive \& expressive vocabulary test (REVT). Seoul: Seoul Community Rehabilitation Center.

Lee, B. W. (2015). Korean grammar. Seoul: Hakjisa.

Lim, S. H. (2010). Changes in word definition ability depending on severity in patients with Alzheimer's disease (Master's thesis). Ewha Womans University, Seoul, Korea.

Marinellie, S. A., \& Johnson, C. J. (2004). Nouns and verbs: a comparison of definitional style. Journal of Psycholinguistic Research, 33, 217-235.

McGregor, K. K. (2009). Semantics in child language disorders. In R. G. Schwartz (Ed.), Handbook of child language disorders (pp. 365-387). New York: Psychology Press.

Moon, H. S. (2001). Literacy and cognitive function in the Korean elderly subjects (Master's thesis). Sungshin University, Seoul, Korea.

National Institute of Korean Language. (2015). Pyojun-Gugeo-Daesajeon. Seoul: Author.

Pae, S., \& Kwak, K. C. (2007). Korean MacArthur-Bates Communicative Development Inventories (KM-B CDI). Seoul: Mindpress.

Park, K. A., \& Kim, Y. T. (2000). A comparat ive study of verbal definitions of concrete nouns between normal children and language-delayed children. Korean Journal of Communication Disorders, 5, 20-37.

Park, S. (2005). Estimating the definition of concrete nouns of school-age children and adults (Master's thesis). Dankook University, Yongin, Korea.

Paul, R., \& Norbury, C. (2012). Language disoders from infancy through adolescence (4th ed.). St. Louis, MO: Elsevier.

Statistics Korea. (2015). Elderly statistics. Seoul: Author.

Vellutino, F. R., Fletcher, J. M., Snowling, M. J., \& Scanlon, D. M. (2004). Specific reading disability (dyslexia): what have we learned in the past four decades? Journal of Child Psychology and Psychiatry, 45, 2-40.

Wallace, G., \& Hammill, D. D. (2002). CREVT2: comprehensive receptive and expressive vocabulary test. Austin, TX: Pro-Ed.

Watson, R. (1985). Towards a theory of definition. Journal of Child Language, 12, 181-197.

Wiig, E. H., \& Secord, W. (1992). Test of Word Knowledge (TOWK). New York: Psychological Corporation. 
Appendix 1. 검사단어

\begin{tabular}{|c|c|c|}
\hline 품사 & 상위친숙도 단어 & 하위친숙도 단어 \\
\hline \multicolumn{3}{|l|}{ 명사(12개) } \\
\hline 구체명사(6개) & 손, 학교, 아버지 & 책, 물, 친구 \\
\hline 추상명사(6개) & 사실, 방법, 문제 & 삶, 전쟁, 정보 \\
\hline 동사(12개) & 찾다, 열다, 잡다, 바꾸다, 나누다, 떨어지다, & 놀라다, 달리다, 사라지다, 움직이다, 태어나다, 좋아하다 \\
\hline 형용사(12개) & 뜨겁다, 똑같다, 무섭다, 날카롭다, 부끄럽다, 커다랗다 & 맵다, 둥글다, 고맙다, 괴롭다, 배고프다, 시끄럽다 \\
\hline
\end{tabular}

Appendix 2. 구체명사의 정의 점수 채점 기준

\begin{tabular}{lll}
\hline 점수 & \multicolumn{1}{c}{ 보통명사 } & \multicolumn{1}{c}{ 예 (아버지) } \\
\hline 1점 & 주요 특성 & 어머니의 반대 개념이고 나를 태어나게 해주신 분 \\
1점 & 상위어 & 가족 구성원 중 한 분 \\
2개 이상이면 1점 & 부수적인 특성 & 어머니의 반대 개념 / 남자 / 낳아주셨다 \\
0점 & 오류 & 오류유형의 예 참고 \\
\hline
\end{tabular}

Appendix 3. 추상명사의 정의 점수 채점 기준

\begin{tabular}{lll}
\hline 점수 & \multicolumn{1}{c}{ 추상명사 } & \multicolumn{1}{c}{ 예 (문제) } \\
\hline 1점 & 주요 특성 & 과제 같이 해결해야 하는 것 \\
1점 & 상위어나 동의어 & 논쟁 / 논의 \\
2개 이상이면 1점 & 부수적인 특성 & 시험칠 때 / 과제 같은 거 / 풀어야 하는 것 \\
0점 & 오류 & 오류유형의 예 참고 \\
\hline
\end{tabular}

Appendix 4. 동사, 형용사의 정의 점수 채점 기준

\begin{tabular}{lll}
\hline 점수 & 동사, 형용사 & \multicolumn{1}{c}{ 예 (똑같다) } \\
\hline 1점 & 주요 특성 & 젓가락 같이 다른 점이 없다. \\
1점 & 동의어 & 동일하다 \\
2개 이상이면 1점 & 부수적인 특성 & 쌍둥이 / 젓가락 / 다름이 없다 \\
0점 & 오류 & 오류유형의 예 참고 \\
\hline
\end{tabular}


Appendix 5. 구체명사의 정의 유형

\begin{tabular}{|c|c|c|c|}
\hline 정의 유형 & 하위 정의유형 & 특성 & 예 \\
\hline \multirow[t]{2}{*}{ 기능적정의 } & 행위자 기능 & 목표단어의 움직임, 생물 뿐만 아니라 무생물이 행위자 역할을 하는 경우도 해당됨 & 손: "무엇을 집을 수 있게 해줘요" \\
\hline & 도구적 기능 & 목표단어로 할 수 있는 기능 & 물: “마실 수 있어요” \\
\hline \multirow[t]{4}{*}{ 지각적 정의 } & 부분 & 목표단어의 실물 중 특징적인 부분 & 손: “다섯 개의 손가락, 지문이 있어요” \\
\hline & 재료 & 목표단어가 무생물일 때, 그의 구성성분 & 책: “종이고 글자가 있어요” \\
\hline & 속성 & $\begin{array}{l}\text { 목표단어의 특유의 여러 가지 속성들(소리, 모양, 크기, 길이, 양, 색, 속도, 온도, 세기, } \\
\text { 맛, 무게 등) }\end{array}$ & 물: “차갑고 무색인 액체” \\
\hline & 관념/추상 & 목표단어의 속성이나 특징에 관한 관념적이거나 추상적인 표현 & 학교: “학문을 배우는 곳이에요” \\
\hline \multirow[t]{6}{*}{ 관계적 정의 } & 배경 & 목표단어의 존재나 기능에 관련된 시간, 조건, 이유 상황 & 물: “목마를 때” \\
\hline & 위치 & 목표단어와 관련된 위치 & 책: “도서관에 많이 있어요” \\
\hline & 비유/비교/대조 & $\begin{array}{l}\text { 목표단어를 ‘-처럼', ‘-같은'을 사용해 다른 단어로 비유하거나 ‘-보다'를 사용하여 비교함. } \\
\text { 또한, 목표단어와 관련된 반대어를 사용하여 비교함 }\end{array}$ & 물: "산소와 같이 지구상에 필요한 거예요" \\
\hline & 부정 & '안' '못’, ‘아니다' 등을 사용하여 다른 유형을 부정 & 아버지: “엄마가 아닌 다른 사람” \\
\hline & 관련실체 & 목표단어와 특히 관련된 사물이나 사람 & 학교: "제자가 있고 선생이 있어” \\
\hline & 원리 & 목표단어를 작동시키는 원리나 목표단어가 만들어진 원리 & $\begin{array}{l}\text { 책: "저자가 많은 줄거리를 써서 팔고 읽고 } \\
\text { 하는 그런 거에요" }\end{array}$ \\
\hline \multirow[t]{4}{*}{ 분류적 정의 } & 특징 상위어 & 목표단어를 포함하는 특징 상위어 & 손: “신체의 일부분” \\
\hline & 일반적인 상위어 & 적절한 상위어 대신 '것(thing)' 혹은 '물건(object)' 같은 단어가 산출되는 경우 & 책: “지식을 얻을 수 있는 것” \\
\hline & 하위어 & 목표단어의 종류 & 책: “소설책, 잡지책이 있어요” \\
\hline & 동의어/유의어 & 목표단어와 같은 뜻을 나타내거나 비슷한 뜻을 나타내는 단어가 산출되는 경우 & 친구: “프랜드 \\
\hline 기타 & 오류 유형 참고 & 위의 정의 유형에 포함되지 않는 경우 & 오류유형의 예 참고 \\
\hline
\end{tabular}

Appendix 6. 추상명사, 동사, 형용사의 정의 유형

\begin{tabular}{|c|c|c|c|}
\hline 정의 유형 & 하위 정의유형 & 특성 & 예 \\
\hline 특징적 정의 & & 목표단어의 특유 핵심 자질들(사전적 정의) & 전쟁: “나라간의 세력 다툼” \\
\hline \multirow{6}{*}{ 관계적 정의 } & 배경 & 목표단어의 존재나 기능에 관련된 시간, 조건, 이유 상황 & 찾다: “물건을 잃어버렸을 때 하는 행동” \\
\hline & 위치 & 목표단어와 관련된 위치 & 달리다: “운동장에서 하지” \\
\hline & 비유/비교/대조 & $\begin{array}{l}\text { 목표단어를 ‘-처럼', ‘-같은'을 사용해 다른 단어로 비유하거나 ‘-보다’를 사용하여 비교함. } \\
\text { 또한, 목표단어와 관련된 반대어를 사용하여 비교함 }\end{array}$ & 날카롭다: "칼 같은 거" \\
\hline & 부정 & '안', '못', '아니다' 등을 사용하여 다른 유형을 부정 & 시끄럽다: “조용하지 않는 거죠” \\
\hline & 관련실체 & 목표단어와 특히 관련된 사물이나 사람 & 맵다: “청양고추” \\
\hline & 원리 & 목표단어를 작동시키는 원리나 목표단어가 만들어진 원리 & $\begin{array}{l}\text { 놀라다: “무서운 거를 봐서 갑자기 심장 박동 } \\
\text { 수가 높아지고 얼굴이 찡그러지면서 소리 } \\
\text { 를 내는 그런 거죠" }\end{array}$ \\
\hline \multirow[t]{4}{*}{ 분류적 정의 } & 특징 상위어 & 목표단어를 포함하는 특징 상위어 & 사실: “보이는 그대로의 현상” \\
\hline & 일반적인 상위어 & 적절한 상위어 대신 '것(thing)' 혹은 '물건(object)' 같은 단어가 산출되는 경우 & 문제: “해결해야 하는 것” \\
\hline & 하위어 & 목표단어의 종류 & 삶: "인생” \\
\hline & 동의어/유의어 & 목표단어와 같은 뜻을 나타내거나 비슷한 뜻을 나타내는 단어가 산출되는 경우 & 잡다: "줍다" \\
\hline 기타 & 오류 유형 참고 & 위의 정의 유형에 포함되지 않는 경우 & 오류유형의 예 참고 \\
\hline
\end{tabular}


Appendix 7. 오류유형

\begin{tabular}{|c|c|c|}
\hline 오류유형 & 설명 & 예 \\
\hline 불충분한정의 & 목표 어휘에 해당하는 주요한 특성이나 상위어에 대한 언급 없이 부수적인 특성을 하나만 이야기 하는 경우 & 달리다: “다리” \\
\hline 제스처 & 목표 어휘를 설명하지 않고, 지시하거나 가리키는 경우 & 손: “(손을 가리키며) 이거잖아” \\
\hline 목표어휘반복 & 목표어휘와 관련된 예가 아닌 단순히 목표 어휘를 포함한 문장이나 목표 어휘를 반복하는 경우 & 달리다: “달리다, 달리다” \\
\hline 개인적인 반응 & 목표 어휘와 관련된 개인적인 생각이나 경험을 이야기하는 경우 & 삶: “지금의 내 삶은 힘들어” \\
\hline 무응답 & 모른다고 응답하거나 반응이 없는 경우 & 정보: “모르겠어요" \\
\hline
\end{tabular}

Appendix 8. 연령 집단과 명사에 따른 정의 점수의 빈도와 비율(\%)

\begin{tabular}{lccc}
\hline Nouns & Young group & Elderly group & $t$ \\
\hline Score 0 & $1.76(14.63)$ & $4.67(38.89)$ & $5.168 * \star *$ \\
Score 1 & $6.73(56.11)$ & $6.69(55.74)$ & -.071 \\
Score 2 & $3.51(29.26)$ & $.64(5.37)$ & $-5.280 * * *$
\end{tabular}

Values are presented as mean (\%).

$* * * p<.001$.

Appendix 9. 연령 집단과 동사에 따른 정의 점수의 빈도와 비율(\%)

\begin{tabular}{lccc}
\hline Verbs & Young group & Elderly group & $t$ \\
\hline Score 0 & $2.31(19.26)$ & $5.40(45.00)$ & $5.135 * * *$ \\
Score 1 & $7.53(62.78)$ & $6.09(50.74)$ & $-2.263 *$ \\
Score 2 & $2.16(17.96)$ & $.51(4.26)$ & $-3.524 * *$
\end{tabular}

Values are presented as mean (\%).

$\star p<.05, * * p<.01, * * * p<.001$.

Appendix 10. 연령 집단과 형용사에 따른 정의 점수의 빈도와 비율(\%)

\begin{tabular}{lccc}
\hline Adjectives & Young group & Elderly group & \multicolumn{1}{c}{$t$} \\
\hline Score 0 & $1.49(12.41)$ & $4.38(36.48)$ & $6.259 * * *$ \\
Score 1 & $8.24(68.70)$ & $7.36(61.56)$ & -1.608 \\
Score 2 & $2.27(18.89)$ & $.22(1.96)$ & $-5.438 * * *$ \\
\hline
\end{tabular}

Values are presented as mean (\%).

$* * * \mathrm{p}<.001$. 


\section{국문초록}

\section{노화에 따른 명사, 동사, 형용사 정의하기 특성 \\ 김예슬' 윤지혜 ${ }^{2}$}

'한림대학교 보건대학원 언어병리학과, ${ }^{2}$ 한림대학교 언어청각학부

배경 및 목적: 노화로 인한 의미론적 처리 능력의 감퇴는 목표어휘에 대한 적절한 내용을 이해하고 관련된 어휘를 산출하는 정의하기 능력에 영향을 줄 수 있다. 우리나라의 품사 사용빈도를 보면 명사와 동사, 형용사가 전체 품사의 약 $90 \%$ 정도를 차지하므로 명사뿐만 아니라 다양한 품사에서 관찰되는 정의하기 능력을 확인할 필요가 있다. 이에 본 연구는 정상 노인을 대상으로 명사, 동사, 형용사 품사 별 정의하기 능력을 살펴보고, 그 수행력을 청년과 비교하여 결과에 따른 임상적 시사점을 제시하고자 하였다. 방법: 정상 노인 45 명과 청년 45 명을 대상으로 총 36 개의 단어에 대한 정의하기 과제를 시행하였다. 각 항목에 대한 대상자의 반응 중에서 30 초 이내의 발화만 을 선택하여 정의반응점수, 반응시간과 정의 유형, 오류 유형을 분석하였다. 결과: 첫째, 정의반응점수는 노년층이 청년층보다 모든 품 사에서 유의하게 낮은 수행력을 보였다. 둘째, 품사별 정의유형은 연령 간 유의미한 차이가 있었다. 셋째, 품사별 정의하기 과제에서 오 류 유형은 연령 간 구체명사, 동사, 형용사에서 유의미한 오류 유형을 보였다. 넷째, 품사별 정의하기의 반응시간에서는 구체명사, 동사, 형용사에서 노년층이 청년층보다 유의하게 느리게 반응하였다. 논의 및 결론: 위의 결과를 토대로 노년층은 의사소통 상황에서 구어적 다양성에 제약이 생겨 새롭고 다양한 단어를 연상하고 생성하는 것에서의 어려움을 보임을 확인하였다.

핵심어: 정의하기, 명사, 동사, 형용사, 노화

이 논문은 2014년 정부(교육부)의 재원으로 한국연구재단의 지원을 받아 수행된 연구임(NRF-2014S1A5A2A03065709).

\section{참고문헌}

강범모, 김흥규(2004). 한국어 형태소 및 어휘 사용 빈도의 분석 2.0. 서울: 고려대학교 민족문화연구원.

강범모, 김흥규(2009). 한국어 사용 빈도. 서울: 한국문화사.

강연욱, 나덕렬, 한승혜(1997). 정신상태간이검사. 서울: 휴브알엔씨.

국립국어원(2015). 표준국어대사전. 서울: 국립국어원

김광해(2003). 기초어휘의 개념과 중요성. 새국어새활, $13,5-29$.

김광해(2003). 등급별 국어 교육용 어휘. 서울: 박이정.

김미배(2014). 의미, 문법 영역에서 상위언어능력에 대한 국내 문헌연구. 언어치료연구, 23, 61-77.

김수련(2015). 건망형 경도인지장애 환자의 추상단어 정의하기 능력의 손상. 연세대학교대학원 박사학위논문.

김수정, 최현주(2012). 노년층의 명사 정의하기 특성. 언어청각장애연구, 17, 107-117.

김영태, 홍경훈, 김경희, 장혜성, 이주연(2009). 수용-표현어휘력검사(REVT). 서울: 서울장애인종합복지관.

김주희(2014). 청각장애인의 명사, 동사, 형용사 정의하기 발달. 대구대학교대학원 석사학위논문.

김향희, 허지희, 김덕용, 김정완(2009). 실어증-신경언어장애 선별검사. 서울: 학지사.

문혜성(2001). 한국 노인의 문식성(Literacy)과 인지기능. 성신여자대학교대학원 석사학위논문.

박경애, 김영태(2000). 언어발달지체아동과 정상아동의 보통명사 정의하기 능력 비교. 언어청각장애연구, 5, 1-19.

박성심(2005). 학령기 아동과 성인의 보통명사 정의하기. 단국대학교대학원 석사학위논문.

배소영, 곽금주(2007). 한국판 맥아더-베이츠 의사소통 발달평가(K MB CDI). 서울: 마인드프레스.

이봉원(2015). (언어치료사를 위한) 한국어문법. 서울: 학지사.

임성희(2010). 알쯔하이머 치매 환자의 단어 정의하기 능력의 변화. 이화여자대학교대학원 석사학위논문.

장현진(2012). $\mathrm{ADHD}$ 아동과 일반아동의 보통명사와 추상명사 정의하기 특성 비교. 용인대학교대학원 석사학위논문.

최진영(2001). 중학교 국어 교과서의 어휘 연구. 계명대학교대학원 석사학위논문.

통계청(2015). 고령자통계. 서울: 통계청. 